Kansas State University Libraries

New Prairie Press

\title{
IDENTIFYING SPECTRA IMPORTANT FOR PREDICTION OF SENESCENT GRASSLAND CANOPY STRUCTURE
}

\author{
Rebecca Phillips \\ Nicanor Saliendra \\ Mark West
}

Follow this and additional works at: https://newprairiepress.org/agstatconference

Part of the Agriculture Commons, and the Applied Statistics Commons

\section{(c) (1) $\Theta(9$}

This work is licensed under a Creative Commons Attribution-Noncommercial-No Derivative Works 4.0 License.

\section{Recommended Citation}

Phillips, Rebecca; Saliendra, Nicanor; and West, Mark (2012). "IDENTIFYING SPECTRA IMPORTANT FOR PREDICTION OF SENESCENT GRASSLAND CANOPY STRUCTURE," Conference on Applied Statistics in Agriculture. https://doi.org/10.4148/2475-7772.1036

This is brought to you for free and open access by the Conferences at New Prairie Press. It has been accepted for inclusion in Conference on Applied Statistics in Agriculture by an authorized administrator of New Prairie Press. For more information, please contact cads@k-state.edu. 
IDENTIFYING SPECTRA IMPORTANT FOR PREDICTION OF SENESCENT GRASSLAND CANOPY

STRUCTURE

Rebecca Phillips ${ }^{1}$

Nicanor Saliendra ${ }^{1}$

USDA-ARS

Northern Great Plains Research Laboratory

PO Box 459

1701-10th AvenueSW Mandan, ND58554

Mark West ${ }^{2}$

USDA-ARS

2150 Centre Avenue

Fort Collins, CO, 80526-8119 


\section{Abstract}

Managers of the nearly 0.5 million ha of public lands in North and South Dakota, USA rely heavily on manual measurements of vegetation properties to ensure conservation of grassland structure for wildlife and forage for livestock. Spectral imaging data may be useful in assessment of large (>100,000 ha) landscapes, as in the Grand River National Grassland (GRNG), South Dakota. Here, we examined the predictive potential for the Advanced High Resolution Spectrometer (AVIRIS) to estimate mixed-grass prairie canopy structural attributes (photosynthetically active vegetation $\left(\mathrm{kg} \mathrm{PV} \mathrm{ha}^{-1}\right)$, non-photosynthetically active vegetation (kg NPV ha $\left.{ }^{-1}\right)$, total standing crop (kg PV+NPV ha $\left.{ }^{-1}\right)$, nitrogen content $\left(\mathrm{kg} \mathrm{N}^{-1}\right)$, and visual estimates of bare ground (\%) in October 2010. We conducted the study on a 36,000-ha herbaceous area using 24 randomly selected plots divided into summit, midslope and toeslope positions. Field data were collected during the AVIRIS flyover, and three approaches for building a prediction model of canopy attributes based on spectra were evaluated based on $\mathrm{R}^{2}$ values. These approaches included Partial Least Squares Regression (PLS), a variable selection method with predictor variables based on functions of the AVIRIS spectra, and a variable selection method using individual bands or combinations of individual bands of spectra as predictors. All variable selection methods involved randomly partitioning the data into training and validations sets and choosing a final prediction model based on model selection frequency. PLS regression out-performed regression models (based on the variable selection methods) with $\mathrm{R} 2$ values of $0.73,0.56,0.62,0.67$, and 0.58 , for PV, NPV, total standing crop, nitrogen content, and bare ground, respectively. 


\section{Introduction}

The US Forest Service (USFS) grassland management plan includes assessment of vegetative properties associated with structure, such as canopy height and biomass, to ensure public lands provide adequate forage and nesting cover for domestic livestock and wildlife habitat (Larivière 2003). Grassland assessments have historically used field-based metrics that measure vegetation structure with a Robel pole (Robel et al. 1970) after livestock removal in October, but these point measurements may not adequately represent the heterogeneous native grassland landscape. Passive, remote-sensing based data provide synoptic views of plant reflectance that are suitable for assessment purposes (Hunt et al. 2003). These satellite or aerial-borne image data have been used in models to assist with assessing grassland structural properties in the southwestern and western U.S during the peak season (June-July), when plants are photosynthetically active (Jacquemoud et al. 1995; Kokaly et al. 1999; Beeri et al. 2007). At the end of the growing season, most of the vegetative canopy is no longer photosynthetically active, and relationships between properties such as grassland biomass and reflectance spectra are not clear for native, heterogeneous grassland canopies (Aase et al. 1987). Remote sensing-based assessment of grasslands in the northern Great Plains requires investigation of plant canopy properties and image data at scales relevant to land managers. Vegetation Indices (VIs) are commonly used to assess grassland canopy properties such as greenness, where the Normalized Difference Vegetation Index (NDVI) or other VIs are employed (Todd et al 1998, Marsett et al 2006, Beeri et al 2007, Guerschman et al 2009, Knox et al 2011, Psomas et al 2011, Wang et al 2011). Each VI relies on application of specific regions of the spectra, but the spectral resolution (band width) varies with sensor data source. Wide- 
band, multi-spectral data, such as those collected by the Landsat TM or the Advanced Spaceborne Thermal Emission and Reflection Radiometer (ASTER) sensors are often manipulated to report particular VI values, such as NDVI. The numbers of bands, however, are typically limited to $<8$. For assessment of grassland at the end of the growing season, when most of the canopy is senescent and no longer photosynthetically active, additional bands of information are needed, according to post-harvest studies in corn, soybean, and wheat crop fields (Daughtry et al. 2004). Hyperspectral sensors, such as the Advanced High Resolution Spectrometer (AVIRIS), provide a greater breadth of information, including narrow bands of the spectra potentially sensitive to changes in senescent material.

Narrow band reflectance data applied to grassland canopies have successfully estimated canopy properties, such as carbon/nitrogen $(\mathrm{C} / \mathrm{N})$ ratio and total standing crop biomass (PV+NPV), during the growing season (Beeri et al. 2007). However remote estimation of these properties post-growing season is problematic because canopies at this time are mixtures of species at various stages of senescence. Mixtures of PV, NPV, and rocks or bare soil within a single pixel of information dramatically increase the error when correlating field plot and spectral reflectance data (He et al. 2010). The need to assess grassland canopy structural properties after livestock removal for the purpose of managing cover for wildlife habitat is clear, but it is not clear how relationships between reflectance data and grassland properties covary for large landscapes when most of the canopy is senescent.

\section{Methods}

\section{Field Site Description}


The Grand River National Grassland (GRNG) is located in northwestern South Dakota, USA $\left(45.7^{\circ} \mathrm{N}, 102.5^{\circ} \mathrm{W}\right.$; Figure 1) within the Northern Great Plains ecoregion(Omernik 1987). About $75 \%$ of the annual precipitation $(350 \mathrm{~mm}$ ) occurs during the growing season (AprilSeptember). Average monthly temperature is highest in July $\left(21^{\circ} \mathrm{C}\right)$ and lowest in January $(-9$ $\left.{ }^{\circ} \mathrm{C}\right)$. Topography ranges from open plains to rolling grassland prairie, with elevations from 670$880 \mathrm{~m}$. Soils are predominantly well-drained, moderately deep, moderately permeable, fineloamy, mixed, superactive, frigid TypicArgiustolls(NRCS). The GRNG is a mixed-grass prairie ecosystem characterized by blue grama [Boutelouagracilis (H.B.K.) Lag. Ex Griffiths] and western wheatgrass [Pascopyronsmithii(Rybd) Lőve]. Many of the GRNG lowlands were farmed in the early $20^{\text {th }}$ century and are now stands of crested wheatgrass [Agropyroncristatum (L) Gaertn.]. The GRNG is seasonally grazed by cattle (May-October), and stocking rates are approximately one animal unit per hectare.

A 100,000 ha area of interest (AOI) in the center of the GRNG was selected for this study, and the targeted area of herbaceous material $(36,000 \mathrm{ha})$ was identified using objectbased classification in Ecognition. We evaluated historical (10 y) reflectance data collected by the Moderate Resolution Imaging Spectrometer (MODIS) sensor to ensure our field sampling points represented the full range of reflectance values found within our AOI over time. The unsupervised classification on the MODIS Enhanced Vegetation Index (EVI) data collected in June and July from 2000 to 2009 indicated there were four Historical Vegetation Index (HVI) classes. These four classes comprised over $98 \%$ of the herbaceous vegetation $A O I$ and were used to stratify the landscape prior to field plot random selection. The four HVI classes represented areas historically high or low in EVI reflectance values. Within each HVI class, we 
randomly selected six plots, and these were separated into three topographic position groups.

Digital Elevation Model (DEM) data, 10-m pixel resolution, were accessed from the U.S.G.S. National Elevation Dataset [http://ned.usgs.gov/(Gesch et al. 2002)]. We modeled the DEM to stratify the landscape into three topographic positions: summits, midslopes or toeslopes(Qin et al. 2009). A total of 24 plots, or 72 points, were sampled during the field campaign in late October, 2010 (Phillips et al. 2012).

\section{Field Data Collection}

At each of the 72 points, vegetation was sampled in four cardinal directions, $3 \mathrm{~m}$ from the center of each plot. We measured standing crop biomass (both PV and NPV), leaf area, canopy height, and canopy nitrogen. Canopy height was recorded using the Robel pole method (Robel et al. 1970; Uresk et al. 2007). We also recorded visual estimates for the percentages of bare soil, senescent vegetation, green vegetation, and litter in the four subplots (Phillips et al. 2012). Total standing crop biomass (TSC, $\mathrm{kg} \mathrm{ha}^{-1}$ ) was calculated as the sum of green PV and senescent NPV and averaged for the four subplots. PV and NPV vegetation was ground separately through a 1-mm mesh screen, and analyzed for total $\mathrm{N}$ using dry combustion on a Carlo Erba Model NA 1500 Series 2 N/C/S analyzer (CE Elantech, Lakewood, NJ). Canopy N content ( $\mathrm{kg} \mathrm{N} \mathrm{ha}^{-1}$ ) was calculated using $\mathrm{N}$ content and mass for both PV and NPV vegetation. $\underline{\text { AVIRIS Data Collection and Correction }}$

The Airborne Visible and InfraRed Imaging Spectrometer (AVIRIS, Jet Propulsion Laboratory, Pasadena, CA, USA) provides calibrated images of spectral radiance in 224 contiguous spectral channels from 400 to $2500 \mathrm{~nm}$ (Green 2001). During a clear, sunny day on October 21, 2010, an aircraft (Twin Otter N331AR) carrying the AVIRIS sensor was flown at an 
altitude of $16 \mathrm{~km}$ over the 72 sites where field plot observations were recorded and vegetation clippings were collected as described above. Radiance data were atmospherically corrected using the Fast Line-of-Sight Atmospheric Analysis of Spectral Hypercubes (FLAASH) module in the ENVI/IDL software

(http://www.ittvis.com/portals/0/tutorials/envi/FLAASH_Hyperspectral.pdf). Data were converted to units of reflectance (scaled between 0 and 10,000). Wavelengths are each end of the spectra were excluded, 366-502 $\mathrm{nm}$ and 2457 to $2500 \mathrm{~nm}$, as well as known regions of high water absorption, 1353 to $1423 \mathrm{~nm}$ and 1812 to $1937 \mathrm{~nm}$ (Beeri et al. 2007).

We used a portable Global Positioning System (GPS, Trimble Geo XT) to collect precise location data for the 72 points (3 topographic positions $\times 24$ plots). Pixel size in the AVIRIS image was $3.5 \mathrm{~m}$, and we extracted raster data (ASCIl format) from $2 \times 2$ pixels surrounding each GPS waypoint. Vegetation indices as listed in Table 1 were calculated for each pixel, and mean values for each group of 4 pixels were calculated for each point to compare with field data.

\section{Statistical Analyses}

We investigated the potential of AVIRIS reflectance values for prediction of PV, NPV, TSC, $\mathrm{N}$ content, and percent bare ground in three separate ways. For one, we fit Partial Least Squares (PLS) (Garthwaite 1994) models using the reflectance collected for all spectral bands. Secondly, we applied a model selection procedure using a suite of VIs as candidate predictors (Table 1) together with topographic position and HVI class for the purpose of building a linear prediction model. Lastly, we applied a model selection procedure to build a linear prediction model based on a subset of spectral bands. The model selected for each prediction method 
was tested by iteratively partitioning the available data at random 1000 times into training and test sets. For each partition, models were fitted to each training set and these were used to predict observations in each test set. The ratio of training samples to test samples in each of the 1000 partitions was chosen as 2:1. Goodness of fit for each model was reported in terms of average $\mathrm{R}^{2}$ across the random partitions, which was calculated by the square of the Pearson correlation between observed and predicted response. Both SAS (SAS System for Windows, copyright $^{\circledR}$ 2002-2008, SAS Institute Inc., Cary, NC, USA) and R software were heavily relied on to carry out computations in this study.

We developed PLS prediction models (one for each dependent variable) in the form $\widehat{\mathrm{Y}}=\mathrm{R}_{x} \cdot \hat{\beta}$ using the method of de Jong (de Jong 1993) where $\widehat{\mathrm{Y}}$ is an $n \times 1$ vector of predictions of vegetative growth and $\mathrm{R}_{x}$ is an $n \times p$ matrix of reflectance values. Each row vector of $\mathrm{R}$ consists of $p$ discrete entries of reflectance values $\mathrm{R}_{x}$ representing the amount of reflectance at band $x$. Reflectance was measured for $p=184$ distinct bands ranging from $500 \mathrm{~nm}$ to $2450 \mathrm{~nm}$ (i.e. $500 \leq x \leq 2450$ ). Leave-one-out cross validation was used on the entire data set to determine the number of PLS factors to be used for PLS regression. We chose the number of PLS factors that minimized the PRESS statistic for each response. This number of factors corresponds to the number of factors that maximizes the $\mathrm{R}^{2}$ based on PRESS statistic. The latter is computed as $\mathrm{R}^{2}=1-\mathrm{SSE} / \mathrm{SST}$ where SSE is the residual sum of squares for the crossvalidated predictions and SST is the (corrected) total sums of squares for the response.

Both the R package 'pls' and the SAS procedure PROC PLS were used to fit the PLS regressions. Both software packages provided the same regression model fits but the $\mathrm{R}$ package 'pls' was used to facilitate simulation for evaluating goodness of fit. Coefficients from the fitted 
PLS equations were plotted against corresponding bands with the intention of identifying bands most important for prediction. Standard errors for the PLS coefficients were bootstrapped using 'random X sampling' and were used to standardize the coefficients that were plotted.

We evaluated 23 narrow-band VIs (Table 1) computed using the AVIRIS spectra. These were included in a model selection approach to determine which VIs was most predictive for each dependent variable. We included the historical reflectance class (HVI) and topographic position group of each sampled site along with VIs as candidate predictors. In addition, we allowed for the squared term for each VI to be included as a predictor as well as any two-way interaction among the VIs, historical reflectance class and topographic position group. Thus 349 regression effectswere entertained as predictors for modeling each canopy property. Our approach for model selection was based on resampling and model selection frequency and incorporated both Akaike and cross-validation criteria. To carry out model selection the following algorithm was used.

\section{Model Selection Algorithm}

Do the following steps 1000 times.

1. Randomly partition the data to form two sets.

a. From each historical reflectance class select 4 plots at random. This will partition the data set into a training set and a validation set. The remaining 2 plots not selected in each historical reflectance class are used to create a validation set. Partitioning in this manner ensures equal representation of both historical reflectance class and topographic position group.

2. Use stepwise regression on the partitioned data to choose a prediction model 
a. Order in which effects enter model based on the Akaike Information Criterion

b. Significance level for effects to enter set at 0.05

c. Significance level for effects to stay set at 0.10

d. Choose the model among the steps of model selection the one with smallest average mean squared prediction error (AMSE) from the validation sample

e. Require model hierarchy so that when interactions between two variables are entered each of these variables is also included in the model.

3. Record the chosen model for each partition (ie. Each Monte Carlo sample)

- Report selected models and model selection frequencies.

The model selection described above was carried out in SAS using the SURVEYSELECT procedure to randomly partition the data and the GLMSELECT procedure with options choose=validate, select=aicc, sle=0.05, sls=0.10, stop=sl and hier=single to carry out model selection for each partition.

Lastly, we investigated application of a selection procedure called the Lasso (Tibshirani 1996)with individual bands, denoted as $R_{x}$, as predictors. For example, bands at 1200,1400 and $2200 \mathrm{~nm}$ would be denoted as $R_{1200}, R_{1400}$ and $R_{2200}$ respectively. The Lasso is a shrinkage and selection method for linear regression. We are using it here to identify spectral bands important for prediction of canopy response. We incorporated the same random partitioning of data strategy with the SAS procedure SURVEYSELECT as used for the VIs and also used the SAS procedure GLMSELECT with options select=lasso and choose=validate for model selection. We reported models with the highest model selection frequencies. 


\section{Results}

\section{$\underline{\text { PLS regression }}$}

The $\mathrm{R}^{2}$ value (based on the PRESS statistic for PLS regression using leave-one-out crossvalidation) is plotted against number of factors used in Figure 1. The number of factors that minimized this statistic was 5 for all canopy responses except for nitrogen, which was 3 . We evaluated the ability of PLS regression to predict canopy responses using Monte Carlo sampling. Sixteen plots ( 4 plots of 6 possible from each of 4 historical reflectance classes) were randomly sampled for the training set for each of 1000 Monte Carlo trials. Data from the remaining eight plots not used in the training dataset comprised the test dataset in each Monte Carlo trail. The fitted PLS regression for each Monte Carlo trial was used to predict observations of canopy response in both the trial and test datasets and the squared correlation coefficient between fitted and observed was computed for all Monte Carlo trails. These were used to test the fitted how well specific regressions could predict observations not used in fitting the models. We report the average $\mathrm{R}^{2}$ and associated standard error across all Monte Carlo samples for both training and test samples in Table 2. The overall fit statistics based on fitting a PLS regression to the entire dataset is reported in Table 3. Standardized regression coefficients of the PLS regressions using the entire dataset for prediction are plotted in Figure 2. Table 4 summarizes regions of the spectra where coefficients differ by 2 standard errors in absolute value from zero. 

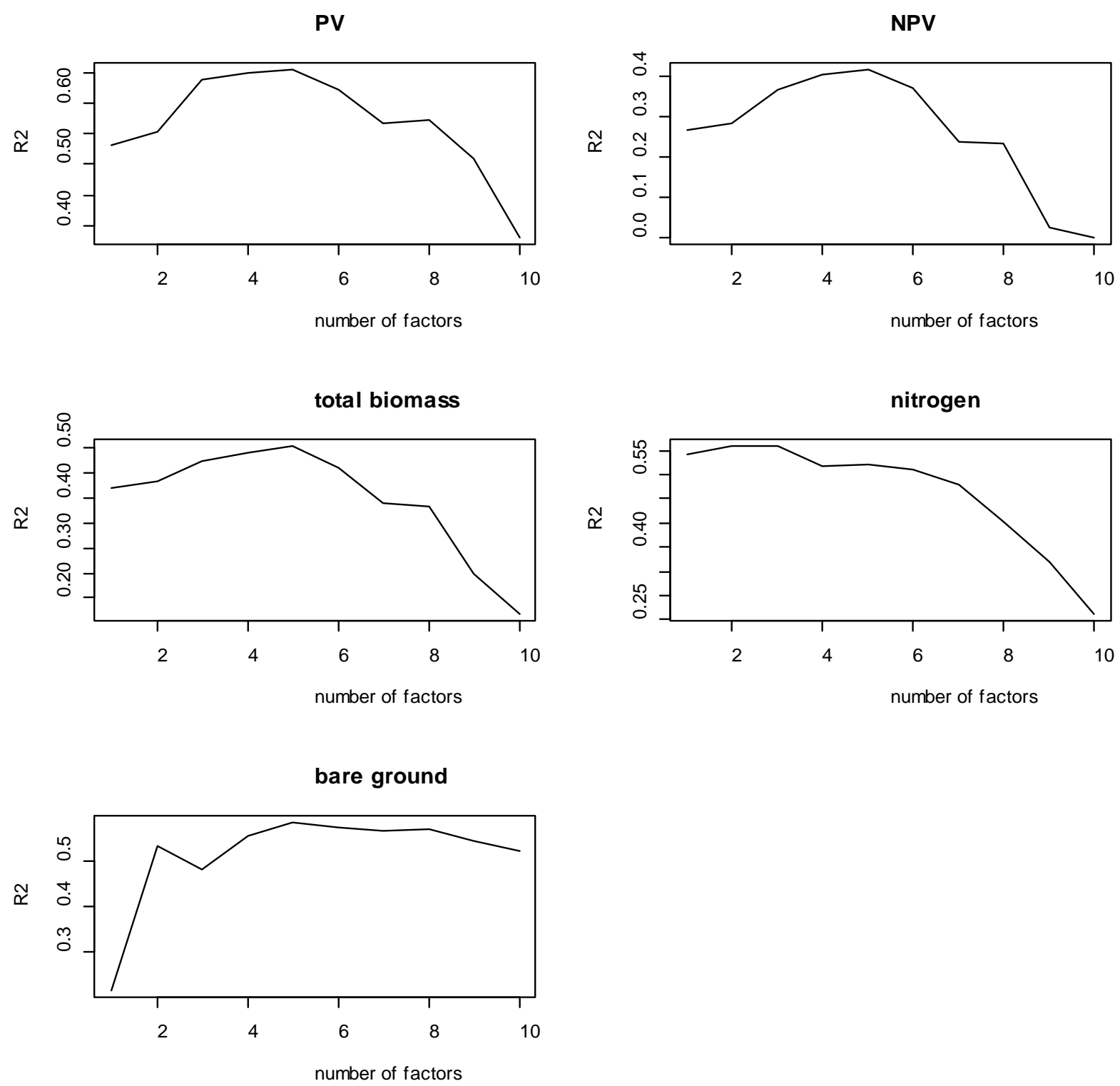

Figure 1: $\mathrm{R}^{2}$ based on PRESS statistic when fitted by PLS regression for each measured canopy characteristic. 


\begin{tabular}{|l|l|l|l|}
\hline Measured Vegetation & \multicolumn{2}{|l|}{ PLS } & \multicolumn{2}{l|}{$R_{\text {test }}^{2}$} \\
\hline Number Factors & \multicolumn{2}{|l|}{$R_{\text {train }}^{2}$} & $0.72(0.117)$ \\
\hline NPV (broen) & 5 & $0.73(0.095)$ & $0.56(0.099)$ \\
\hline Biomass & 5 & $0.55(0.078)$ & $0.63(0.094)$ \\
\hline N & 5 & $0.62(0.075)$ & $0.67(0.070)$ \\
\hline Bare Ground & 3 & $0.67(0.056)$ & $0.58(0.200)$ \\
\hline
\end{tabular}

Table 2: Average $\mathrm{R}^{2}$ with standard error based on PLS fit for both training and test sets for all 1000 Monte Carlo trials.

\begin{tabular}{|c|c|c|c|c|c|}
\hline & \multicolumn{5}{|c|}{ Cumulative Percent Variation Explained } \\
\hline & Factor 1 & Factor 2 & Factor 3 & Factor 4 & Factor 5 \\
\hline PV (green) & 58.8 & 60.1 & 69.6 & 71.0 & 73.7 \\
\hline NPV (brown) & 33.0 & 35.6 & 45.3 & 49.8 & 54.0 \\
\hline Biomass & 46.8 & 48.2 & 54.2 & 57.3 & 60.8 \\
\hline $\mathrm{N}$ & 63.2 & 64.8 & 66.0 & & \\
\hline Bare ground & 30.3 & 49.1 & 55.2 & 62.3 & 66.5 \\
\hline Reflectance $^{*}$ & 51.9 & 96.0 & 98.5 & 98.9 & 99.2 \\
\hline
\end{tabular}

Table 3: $\mathrm{R}^{2}$ by Factor based on PLS fit for each variable using all data. $\mathrm{R}^{2}$ for reflectance based on jointly fitted model. 

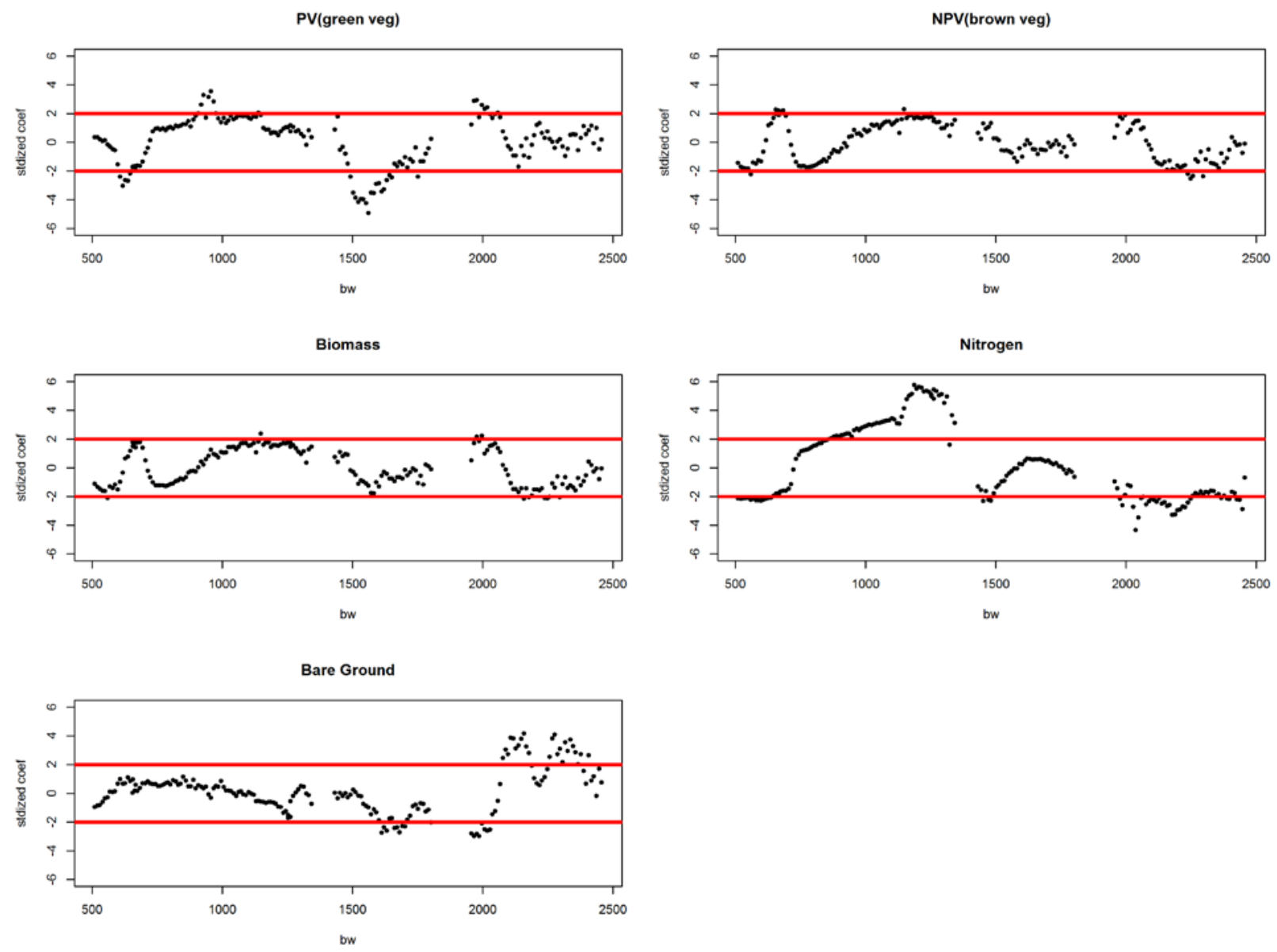

Figure 2: Standardized coefficients for PLS regression based on fitting entire dataset.

\begin{tabular}{|l|l|l|}
\hline Measured Vegetation & B<-2 & B>2 \\
\hline PV (green) & $600-650 \mathrm{~nm}, 1500-1750 \mathrm{~nm}$ & $\begin{array}{l}900-1150 \mathrm{~nm}, 1950-2050 \\
\mathrm{~nm}\end{array}$ \\
\hline NPV (brown) & $550 \mathrm{~nm}, 2200-2300 \mathrm{~nm}$ & $650-690 \mathrm{~nm}, 1150 \mathrm{~nm}$ \\
\hline Biomass & $560 \mathrm{~nm}, 2150-2300 \mathrm{~nm}$ & $1150 \mathrm{~nm}, 1980-2000 \mathrm{~nm}$ \\
\hline $\mathrm{N}$ & $500-640 \mathrm{~nm}, 1450-1500 \mathrm{~nm},>2000 \mathrm{~nm}$ & $850-1350 \mathrm{~nm}$ \\
\hline Bare & $1600-2000 \mathrm{~nm}$ & $2000-2400 \mathrm{~nm}$ \\
\hline
\end{tabular}

Table 4: Regions of extreme spectral absorption or reflectance. Regions with $B<-2$ suggest bands of absorption whereas regions with $B>2$ suggest reflectance.

$\underline{\text { Model Selection using VIs }}$ 
We report models selected with the highest model selection frequencies in Table 5 using the model selection algorithm described for VIs. The model for each of the canopy response is listed under the column with the header 'indices'. For example, the model most frequently selected for predicting N was NDVI which was selected 370 of 1000 times among the Monte Carlo trials. For the case of PV, MTVI2 was selected 379 times and MTVI2+MTVI2 ${ }^{2}$ was selected 277 times but we reported the model selected as the quadratic model with selection frequency $651=379+271$ as the quadratic regression could do no worse than the linear model for prediction of PV.

\begin{tabular}{|l|l|l|l|l|}
\hline Measured & \multicolumn{4}{|l|}{ Model Selection } \\
\hline Vegetation & Indices & \multicolumn{4}{|l|}{ Frequency } & $R_{\text {train }}^{2}$ \\
\hline PV (green) & MTVI2+ MTVI2 & 651 & $0.70(0.112)$ & $0.68(0.141)$ \\
\hline NPV (brown) & SWIR32 & 445 & $0.43(0.059)$ & $0.45(0.125)$ \\
\hline Biomass & SWIR32 & 764 & $0.53(0.055)$ & $0.55(0.114)$ \\
\hline N & NDVI & 370 & $0.62(0.051)$ & $0.63(0.108)$ \\
\hline Bare ground & REI+ SWIR32 & 325 & $0.61(0.092)$ & $0.58(0.175)$ \\
\hline
\end{tabular}

Table 5: Selection frequencies and average $\mathrm{R}^{2}$ and its standard error for both training and validation sets for all 1000 Monte Carlo trials.

Model selection using Individual Bands

Models selected with the model building algorithm of the Lasso previously mentioned using individual bands as candidate predictors are reported in Table 6 for each of the canopy responses. All models selected from the Lasso algorithm included band $R_{2447}$ in the model 
except for PV. We note that results for nitrogen reported below the most frequently selected model was the intercept with a model selection frequency of 167 . However band $R_{1073}$ was selected along with $\mathrm{R}_{2447}$ in 61 occurrences only with the addition of one or two other bands in the 1950-1990nm range. Therefore we reported it as a frequently occurring model.

\begin{tabular}{|l|l|l|l|l|}
\hline \multirow{2}{*}{$\begin{array}{l}\text { Veasured } \\
\text { Vegetation }\end{array}$} & \multicolumn{4}{|l|}{ LASSO } \\
\hline PV (green) & $R_{773} R_{1987}$ & 210 & $0.61(0.085)$ & $0.61(0.105)$ \\
\hline NPV (brown) & $R_{1283} R_{2447}$ & 442 & $0.42(0.057)$ & $0.43(0.117)$ \\
\hline Biomass & $R_{1073} R_{2447}$ & 301 & $0.51(0.080)$ & $0.52(0.098)$ \\
\hline$N$ & $R_{1073} R_{2447}$ & 157 & $0.66(0.060)$ & $0.67(0.074)$ \\
\hline Bare ground & $R_{1283} R_{1333} R_{2447}$ & 228 & $0.58(0.098)$ & $0.62(0.175)$ \\
\hline
\end{tabular}

Table 6: Average $\mathrm{R}^{2}$ with standard error based on the model determined from the LASSO selection method for both training and validation sets for all 1000 Monte Carlo trials.

\section{Summary}

We report how narrow band imagery collected at the AVIRIS sensor could be modeled to assess grassland canopy structural properties post-growing season using three modeling approaches in terms of model $\mathrm{R}^{2}$ only. These approaches differed with regard to how spectral reflectance was used for prediction. The first approach, PLS, used all bands of the spectra in a linear regression model of the form $\widehat{Y}=R_{x} \cdot \hat{\beta}$ where $R_{x}$ represents the spectral reflectance measured at each spectral band $\mathrm{x}$ and with $\hat{\beta}$ determined using an algorithm that uses a factor decomposition of the covariance between the response $Y$ and $R_{x}$. The number of factors chosen 
for decomposition and the computation of $\hat{\beta}$ was the number that minimized the PRESS statistic. The second was a model building approach, based on known VIs (Table 1), each of which represented a functional form of reflectance at select bands, $R_{x}$, for prediction of a specific canopy property. The crux of this approach was based on Monte Carlo sampling where the data was randomly partitioned into training and validation sets 1000 times. For each partition the model with the smallest average mean squared prediction error of the validation set was selected from those identified in a stepwise regression and stored in a list of candidate models. The model with the highest model selection frequency was reported (Table 5) for each canopy trait. The last approach also used a model selection procedure with the same Monte Carlo scheme but each spectral band was considered as a candidate predictor rather than a vegetation index. Model selection for each partition was based on the Lasso (Tibshirani 1996) because we felt it would avoid excessive variety of models in a final list of candidate models. The model with the highest model selection frequency based on the Lasso for each canopy trait is shown in Table 6. For each type of model, a final round of evaluation was performed with Monte Carlo sampling by randomly splitting the data into training and test sets 1000 times, fitting the model on the training set and using the fitted model for prediction on each test set. The coefficient of determination and its standard error was reported across the 1000 Monte Carlo partitions.

Application of AVIRIS spectral reflectance data during time periods when plants are senescent shows promise despite the challenges of identifying the spectral regions most important for prediction of canopy properties. The model selected by Lasso for prediction of $P V$, for example, identified $R_{793}$ and $R_{1987}$, although band 793 had only a moderately sized 
coefficient for PLS regression. These results indicated 1) that green vegetation (PV) and N content can be predicted reasonably well $\left(R^{2}>0.60\right)$, and 2$)$ contrasting bands of spectra are most useful for estimating grassland canopy structure. 


\section{Work Cited}

Aase, J. K., A. B. Frank, et al. (1987). "Radiometric reflectance measurements of Northern Great plains rangeland and crested wheatgrass pastures." Journal of Range Management40(4): 299-302.

Beeri, O., R. Phillips, et al. (2007). "Estimating forage quantity and quality using aerial hyperspectral imagery for northern mixed-grass prairie." Remote Sensing of Environment110(2): 216-225.

Daughtry, S. T., J. E. R. Hunt, et al. (2004). "Assessing crop residue cover using shortwave infrared reflectance." Remote Sensing of Environment90: 126-134.

de Jong, S. (1993). "SIMPLS: An Alternative Approach to Partial Least Squares Regression." Chemometrics and Intelligent Laboratory Systems 18: 251-263.

Garthwaite, P. H. (1994). " An interpretation of Partial Least Squares. J. Amer. Statist. Ass.89: 122-127.

Gesch, D. M., S. Oimoen, et al. (2002). "The national elevation dataset." Photogrammetric Engineering \& Remote Sensing68: 5-11.

Green, R. O. (2001). Measuring the spectral expression of Carbon Dioxide in the solar reflected spectrum with AVIRIS. Proceedings of the 10th JPL Airborne Earth Science Workshop (R. O. Green ed.), JPL Publication. Pasadena, California.

He, Y. and A. Mui (2010). "Scaling up semi-arid grassland biochemical content from the leaf to the canopy level: Challenges and opportunities." Sensors10(12): 11072-11087. 
Hunt, R. E., Jr., J. H. Everitt, et al. (2003). "Applications and research using remote sensing for rangeland management." Photogrammetric Engineering \& Remote Sensing69(6): 675693.

Jacquemoud, S., F. Baret, et al. (1995). "Extraction of vegetation biophysical parameters by inversion of the PROSPECT+SAIL models on sugarbeet canopy reflectance data. Application to TM and AVIRIS sensors." Remote Sensing of Environment52: 163-172.

Kokaly, R. F. and R. N. Clark (1999). "Spectroscopic Determination of Leaf Biochemistry Using Band-Depth Analysis of Absorption Features and Stepwise Multiple Linear Regression." Remote Sensing of Environment67(3): 267-287.

Larivière, S. (2003). "Edge Effects, Predator Movements, and the Travel-Lane Paradox. ." Wildlife Society Bulletin 31: 315-320.

NRCS. "Official Soil Series Descriptions." Retrieved 10 February, 2004, from http://soils.usda.gov/technical/classification/osd/index.html.

Omernik, J. M. (1987). "Ecoregions of the conterminous United States." Annals of the Association of American Geographers77(1): 118-125.

Phillips, R. L., M. Ngugi, et al. (2012). "Mixed grass prairie canopy structure and spectral reflectances varies with topographic position " Environmental Managementin press.

Qin, C. Z., A. X. Zhu, et al. (2009). "Quantification of spatial gradation of slope positions." Geomorphology110: 152-161.

Robel, R. J., J. N. Briggs, et al. (1970). "Relationships between visual obstruction measurements and weight of grassland vegetation." Journal of Range Management23: 296-297. 
Tibshirani, R. (1996). "Regression shrinkage abd selection via the lasso." J. Royal Statist. Soc. B.58: $267-288$.

Uresk, D. W. and T. A. Benson (2007). "Monitoring with a modified Robel pole on meadows in the Central Black Hills of South Dakota." Western North American Naturalist67: 46-50. 
Table 1. Vegetation Indices (VIs) calculated from Airborne Visible-InfraRed Imaging Spectrometer (AVIRIS) reflectance data derived following atmospheric correction with Fast Line-of-sight Atmospheric Analysis of Spectral Hypercubes (FLAASH).

\begin{tabular}{|c|c|c|}
\hline Vegetation Index & Equation & Reference \\
\hline $\begin{array}{l}\text { ARI1, Anthocyanin Reflectance } \\
\text { Index } 1\end{array}$ & $\left(1 / R_{550}\right)-\left(1 / R_{705}\right)$ & Gitelson et al 2001 \\
\hline $\begin{array}{l}\text { ARI2, Anthocyanin Reflectance } \\
\text { Index } 2\end{array}$ & $\mathrm{R}_{802} *\left(1 / \mathrm{R}_{550}-1 / \mathrm{R}_{705}\right)$ & Gitelson et al 2001 \\
\hline $\begin{array}{l}\text { CAI, Cellulose Absorption } \\
\text { Index }\end{array}$ & $0.5^{*}\left(\mathrm{R}_{1997}+\mathrm{R}_{2198}\right)-\mathrm{R}_{2098}$ & Daughtry 2001 \\
\hline MSI, Moisture Stress Index & $\mathrm{R}_{1602} / \mathrm{R}_{822}$ & Hunt and Rock 1989 \\
\hline $\begin{array}{l}\text { MTVI1, Modified Transformed } \\
\text { Vegetation Index } 1\end{array}$ & $1.2 *\left(1.2 *\left(\mathrm{R}_{802}-\mathrm{R}_{550}\right)-2.5 *\left(\mathrm{R}_{638}-\mathrm{R}_{550}\right)\right)$ & Haboudane et al 2004 \\
\hline $\begin{array}{l}\text { MTVI2, Modified Transformed } \\
\text { Vegetation Index } 2\end{array}$ & $\begin{array}{l}1.5 *\left(1.2 *\left(\mathrm{R}_{802}-\mathrm{R}_{550}\right)-2.5 *\left(\mathrm{R}_{638}-\mathrm{R}_{550}\right)\right) / \\
\operatorname{SQRT}\left(2 *\left(\mathrm{R}_{802}+1\right)^{2}-\left(6 * \mathrm{R}_{802}-5 * \operatorname{SQRT}\left(\mathrm{R}_{638}\right)-0.5\right)\right.\end{array}$ & Haboudane et al 2004 \\
\hline $\begin{array}{l}\text { NDII, Normalized Difference } \\
\text { Infrared Index }\end{array}$ & $\left(\mathrm{R}_{822}-\mathrm{R}_{1652}\right) /\left(\mathrm{R}_{822}+\mathrm{R}_{1652}\right)$ & Jackson et al 2004 \\
\hline $\begin{array}{l}\text { NDLI, Normalized Difference } \\
\text { Lignin Index }\end{array}$ & $\begin{array}{l}\left(\operatorname{LOG}\left(1 / \mathrm{R}_{1752}\right)-\operatorname{LOG}\left(1 / \mathrm{R}_{1682}\right)\right) /\left(\operatorname{LOG}\left(1 / \mathrm{R}_{1712}\right)+\right. \\
\left.\operatorname{LOG}\left(1 / \mathrm{R}_{1682}\right)\right)\end{array}$ & Serrano et al 2002 \\
\hline $\begin{array}{l}\text { NDNI, Normalized Difference } \\
\text { Nitrogen Index }\end{array}$ & $\begin{array}{l}\left(\operatorname{LOG}\left(1 / \mathrm{R}_{1512}\right)-\operatorname{LOG}\left(1 / \mathrm{R}_{1682}\right)\right) /\left(\operatorname{LOG}\left(1 / \mathrm{R}_{1512}\right)+\right. \\
\left.\operatorname{LOG}\left(1 / \mathrm{R}_{1682}\right)\right)\end{array}$ & Serrano et al 2002 \\
\hline $\begin{array}{l}\text { Normalized Difference } \\
\text { Senescent Vegetation Index, }\end{array}$ & $\left(\mathrm{R}_{2028}-\mathrm{R}_{638}\right) /\left(\mathrm{R}_{2028}+\mathrm{R}_{638}\right)$ & Marsett et al 2006 \\
\hline $\begin{array}{l}\text { NDVI, Normalized Difference } \\
\text { Vegetation Index }\end{array}$ & $\left(\mathrm{R}_{802}-\rho_{638}\right) /\left(\mathrm{R}_{802}+\mathrm{R}_{638}\right)$ & Tucker 1979 \\
\hline $\begin{array}{l}\text { NDVI705, Red Edge } \\
\text { Normalized Difference }\end{array}$ & $\left(\mathrm{R}_{754}-\mathrm{R}_{705}\right) /\left(\mathrm{R}_{754}+\mathrm{R}_{705}\right)$ & Sims and Gamon 2002 \\
\hline $\begin{array}{l}\text { NDWI, Normalized Difference } \\
\text { Water Index }\end{array}$ & $\left(\mathrm{R}_{1652}-\mathrm{R}_{832}\right) /\left(\mathrm{R}_{1652}+\mathrm{R}_{832}\right)$ & $\begin{array}{l}\text { modified from Gao } \\
1995\end{array}$ \\
\hline $\begin{array}{l}\text { OSAVI , Optimized Soil } \\
\text { Adjusted Vegetation Index }\end{array}$ & $1.16 *\left(\mathrm{R}_{802}-\mathrm{R}_{675}\right) /\left(\mathrm{R}_{802}+\mathrm{R}_{675}+0.16\right)$ & Haboudane et al 2002 \\
\hline $\begin{array}{l}\text { PRI, Photochemical Reflectance } \\
\text { Index }\end{array}$ & $\left(\mathrm{R}_{570}-\mathrm{R}_{531}\right) /\left(\mathrm{R}_{570}+\mathrm{R}_{531}\right)$ & Gamon et al 1997 \\
\hline $\begin{array}{l}\text { PSRI, Plant Senescence } \\
\text { Reflectance Index }\end{array}$ & $\left(\mathrm{R}_{685}-\mathrm{R}_{502}\right) / \mathrm{R}_{754}$ & Merzlyak et al 1999 \\
\hline REI, Red Edge Index & $\mathrm{R}_{705} / \mathrm{R}_{754}$ & Zhang et al 2011 \\
\hline $\begin{array}{l}\text { SATVI, Soil Adjusted Total } \\
\text { Vegetation Index }\end{array}$ & $\left(\left(\mathrm{R}_{2028}-\mathrm{R}_{638}\right) /\left(\mathrm{R}_{2028}+\mathrm{R}_{638}+0.5\right) * 1.5\right)-\mathrm{R}_{2218} / 2$ & Marsett et al 2006 \\
\hline $\begin{array}{l}\text { SR71, Simple Ratio as in } \\
\text { Landsat Band7/Band1 }\end{array}$ & $\mathrm{R}_{2218} / \mathrm{R}_{521}$ & Phillips et al 2012 \\
\hline
\end{tabular}


SWIRDVI, SWIR Difference

Vegetation Index

TCARI , Transformed

Chlorophyll Absorption

- n

TCARI/OSAVI

WBI, Water Band Index
$\left(\mathrm{R}_{2128}-\mathrm{R}_{1642}\right) /\left(\mathrm{R}_{2128}+\mathrm{R}_{1642}\right)$

$3 *\left(\left(\mathrm{R}_{705}-\mathrm{R}_{675}\right)-0.2 *\left(\mathrm{R}_{705}-\mathrm{R}_{550}\right) *\left(\mathrm{R}_{705} / \mathrm{R}_{675}\right)\right)$

TCARI / OSAVI

$\mathrm{R}_{899} / \mathrm{R}_{967}$ this study

Haboudane et al 2002

Zhang et al 2011

Penuelas et al 1995 